
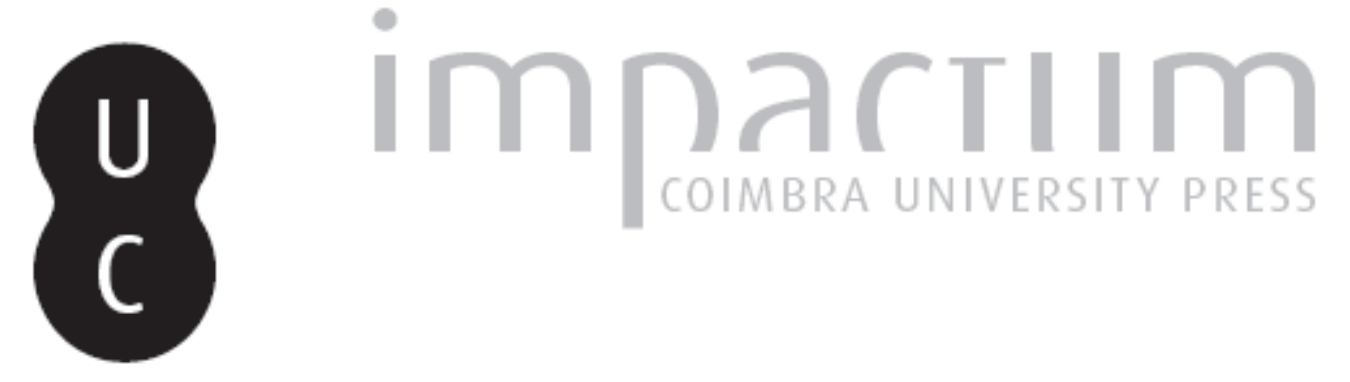

\title{
Genética populacional de três polimorfismos intragénicos do gene da doença de Machado-Joseph (MJD1) na Região Centro de Portugal e nos Açores
}
Autor(es):
Manco, Licínio; Oliveira, Ana Luísa; Abade, Augusto
Publicado por: CIAS - Centro de Investigação em Antropologia e Saúde
URL persistente:
URI:http://hdl.handle.net/10316.2/41244
DOI:
DOI:http://dx.doi.org/10.14195/2182-7982_17_8
Accessed : $\quad$ 26-Apr-2023 12:47:56

A navegação consulta e descarregamento dos títulos inseridos nas Bibliotecas Digitais UC Digitalis, UC Pombalina e UC Impactum, pressupõem a aceitação plena e sem reservas dos Termos e Condições de Uso destas Bibliotecas Digitais, disponíveis em https://digitalis.uc.pt/pt-pt/termos.

Conforme exposto nos referidos Termos e Condições de Uso, o descarregamento de títulos de acesso restrito requer uma licença válida de autorização devendo o utilizador aceder ao(s) documento(s) a partir de um endereço de IP da instituição detentora da supramencionada licença.

Ao utilizador é apenas permitido o descarregamento para uso pessoal, pelo que o emprego do(s) título(s) descarregado(s) para outro fim, designadamente comercial, carece de autorização do respetivo autor ou editor da obra.

Na medida em que todas as obras da UC Digitalis se encontram protegidas pelo Código do Direito de Autor e Direitos Conexos e demais legislação aplicável, toda a cópia, parcial ou total, deste documento, nos casos em que é legalmente admitida, deverá conter ou fazer-se acompanhar por este aviso.

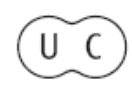




\section{Antropologia Portuguesa}

$16-17 \cdot 1999-2000$

Departamento de Antropologia | Universidade de Coimbra 


\title{
Genética populacional de três polimorfismos intragénicos do gene da doença de Machado-Joseph (MJD1) na Região Centro de Portugal e nos Açores
}

\author{
Licínio Manco, Ana Luísa Oliveira, Augusto Abade \\ Departamenta de Antropologia \\ Universidade de Coimbra \\ 3000-056 Coimbra, Portugal \\ Imanco@ci.uc.pt
}

\section{Resumo}

Neste trabalho procedemos ao estudo de três polimorfismos intragénicos do gene da doença de Machado-Joseph (669A/G; 987C/G e 1118A/C) em duas amostras populacionais de indivíduos saudáveis não aparentados e não pertencentes a famílias MJD, das regiōes Centro de Portugal e Açores. As frequências alélicas encontradas não diferem das publicadas para outras populações de origem Europeia. Foram encontrados os haplótipos comuns G-G-C e A-C-A, com frequências de $82 \%$ e $15,6 \%$, respectivamente, na região Centro de Portugal e $80 \%$ e 18,9\%, respectivamente, nos Açores, indicando serem estes os haplótipos originais do gene MJDI. Considerando estudos haplotípicos semelhantes em famílias MJD, os resultados sugerem uma origem antiga e única da mutação MJD no haplótipo original menos comum A-C-A, numa época provavelmente anterior à separaçāo dos grupos étnicos asiático e europeu. A associação do haplótipo GG-C à mutação MJD, comum em famílias Portuguesas, terá tido uma origem bem mais recente, possivelmente por um mecanismo de conversão génica ou recombinação entre dois genes homólogos, que transferiu a mutação original do haplótipo A-C-A para o haplótipo comum G-G-C.

\section{Palavras-chave}

Doença de Machado-Joseph, MJD, gene MJD1, haplótipos, polimorfismos, Portugal

\footnotetext{
Abstract

In this work we have studied three intragenic polymorphisms (669A/G; $987 \mathrm{C} / \mathrm{G}$ and $1118 \mathrm{~A} / \mathrm{C}$ ) in the Machado-Joseph disease gene in normal population samples
} 
of unrelated individuals with no known relationships to MJD families, from Central Portugal and Azores Islands. The allele frequencies are similar to those found in other European populations. The haplotypic analysis showed two common haplotypes, G-G-C and A-C-A, with $82 \%$ and $15,6 \%$, respectively, in Central Portugal and $80 \%$ and $18,9 \%$, respectively, in Azores, demonstrating these to be the original haplotypes in the $M J D /$ gene. Considering previous similar haplotypic studies with MJD families, the results suggest a single and old MJD mutation in the less common original haplotype A-C-A, that occurred probably before the separation of European and Asian ethnic groups. The linkage of the G-G-C haplotype to the MJD mutation, commonly present in the Portuguese population, cannot be very old and probably occurred as the result of a gene conversion or recombination event that transferred the original mutation from the AC-A haplotype to the common G-G-C haplotype.

\section{Key words}

Machado-Joseph disease, MJD, $M J D I$ gene, haplotype analysis, polymorphisms, Portugal

\section{Introdução}

A doença de Machado-Joseph (MJD) é uma doença neurodegenerativa de início tardio, com transmissão autossómica dominante, e caracterizada clinicamente por ataxia cerebelosa, oftalmoplegia externa progressiva e sinais piramidais a que se podem adicionar outros sintomas (Coutinho e Andrade, 1978).

As primeiras descrições da MJD foram feitas em famílias originárias dos Açores (Nakano et al., 1972; Woods e Schaumburg, 1972; Rosenberg et al., 1976). A doença foi mais tarde identificada no continente Português (Lima e Coutinho, 1980) e noutras famílias de diferentes origens étnicas (Healton et al., 1979; Sequeiros e Coutinho, 1993), sendo hoje considerada a ataxia dominante mais comum em todo o mundo (Silveira et al., 1996).

A alteração génica responsável pela doença consiste numa expansão do tripleto CAG na região codificante do gene MJDI (Kawaguchi et al., 1994), localizado no cromossoma 14q32.1 (Takiyama et al., 1993). Nos indivíduos normais, a sequência repetitiva apresenta 12 a 41 unidades CAG e nos cromossomas expandidos 61 a 86 repetições do tripleto 
(Kawaguchi et al., 1994; Maciel et al., 1995, 1999; Maruyama et al., 1995). A proteína ataxina-3 é o produto génico responsável pelo processo de degenerescência neuronal, mas cuja função permanece desconhecida.

A prevalência da doença nos Açores continua a ser maior do que em qualquer outra parte do mundo, particularmente na ilha das Flores, onde 1 em cada 103 habitantes é doente, I em cada 34 é portador do gene mutado e 1 em cada 21 está em risco para a doença (Lima et al., 1998).

A origem da mutação MJD nas diversas populações tem vindo a ser discutida nos anos mais recentes (Stevanin et al., 1995, 1997; Gaspar et al., 2001). Nos Açores, a doença distribui-se fundamentalmente por duas ilhas, Flores e S. Miguel, tendo sido sugerido que o gene mutante terá sido levado do continente para os Açores durante o seu período de povoamento (Sequeiros e Coutinho, 1993). A distribuição geográfica e reconstrução genealógica das familias afectadas com MJD mostrou que houve a introdução de dois efeitos fundadores no arquipélago dos Açores, um nas Flores e outro em São Miguel (Lima et al., 1998).

O estudo de haplótipos construídos com marcadores moleculares próximos do locus da MJD e com polimorfismos intragénicos do gene $M J D l$, demonstrou a presença em Portugal Continental de dois haplótipos em famílias afectadas com MJD e de apenas um haplótipo na maioria das famílias MJD de origem não Portuguesa distribuídas pelo mundo (Gaspar et al., 2001). Nas famílias MJD Açorianas, os dois haplótipos encontramse distribuídos especificamente pelas ilhas de S. Miguel e Flores (Gaspar et al., 2001), vindo a confirmar a presença dos dois efeitos fundadores no arquipélago dos Açores como havia sido previamente sugerido pelos dados genealógicos (Lima et al., 1998).

$\mathrm{O}$ estudos moleculares não permitiram todavia ainda esclarecer se ocorreram eventos mutacionais independentes em cada um dos países onde foram encontradas famílias com MJD ou se terá havido uma origem única da mutação, após o que se terão originado haplótipos diferentes a partir de um haplótipo original.

Neste trabalho procedemos ao estudo de três polimorfismos intragénicos descritos no gene MJDI [669A/G (212Met/VaI) (Goto et al., 1997); 987C/G (318Arg/Gly) (Kawaguchi et al., 1994); e 1118A/C (Stop/Tyr) (Goto et al., 1997; Stevanin et al., 1997)], em duas amostras populacionais de indivíduos saudáveis não aparentados e não pertencentes a famílias MJD, das regiões Centro de Portugal e Açores, tendo em vista 
contribuir para o esclarecimento da origem da mutação. Foram estimadas as frequências alélicas, feita a análise de haplótipos e comparados os resultados com os dados publicados para outras populações.

\section{Material e Métodos}

Foram utilizadas amostras de sangue total de indivíduos saudáveis não aparentados e não pertencentes a famílias MJD, naturais da região Centro de Portugal $(\mathrm{N}=85)$ e dos Açores (ilhas Terceira, São Jorge e Faial) $(\mathrm{N}=45)$. O DNA genómico foi extraído a partir dos leucócitos utilizando os métodos de extracção com fenol-clorofómio (Sykes, 1983) ou salting-out (Miller et al., 1988).

O polimorfismo 669A/G foi estudado por PCR, utilizando os primers MJDIVSR e MJD734R (Maciel et al., 1999). Os fragmentos amplificados foram submetidos a análise por Single Strand Conformational Polymorphism (SSCP), num mini-gel vertical de poliacrilamida $(7.2 \times 10.2 \mathrm{~cm})$ com $10 \%$ acrilamida-bisacrilamida $(\mathrm{C}=1.3 \%), 10 \%$ glicerol e $50 \mathrm{mM}$ TBE, $\mathrm{pH} 8,3$ e coloração por nitrato de prata segundo Bloom et al. (1987).

O marcador $987 \mathrm{C} / \mathrm{G}$ foi estudado após amplificaçāo por PCR com os primers MJD52 e MJD70 (Kawaguchi et al., 1994). Os produtos amplificados foram digeridos com MspAl I e os fragmentos submetidos a electroforese horizontal em gel de poliacrilamida 10\% (Luís e Caeiro, 1995) e coloração por nitrato de prata segundo Budowle et al. (1991).

A substituição nucleotídica $1118 \mathrm{~A} / \mathrm{C}$ foi estudada por PCR diferencial, utilizando o oligonucleótido directo MJD52 (Kawaguchi et al., 1994) e os primers reversos MJD-TAA e MJD-TAC (Stevanin et al., 1997) específicos para cada um dos alelos A e C, respectivamente. Os produtos de PCR foram submetidos a electroforese em agarose (2\%) com brometo de etídio e analisados à luz ultravioleta.

A análise do desequilíbrio gamético entre pares de marcadores (polimorfismos 669A/G-987C/G; 669A/G-1118A/C e 987C/G-1118A/C) foi efectuada apenas com os genótipos em que foi possível determinar a fase. Os haplótipos entre os três polimorfismos (669A/G - 987C/G $1118 \mathrm{~A} / \mathrm{C}$ ) foram estabelecidos tendo em conta a existência de desequilíbrio gamético entre os pares de marcadores. 
As frequências alélicas foram estimadas por contagem directa. O cálculo das frequências haplotípicas, do desequilíbrio gamético, dos valores esperados de heterozigotia, do equilibrio de Hardy-Weinberg e outros valores estatísticos foi efectuado recorrendo ao software Arlequin versão 2.000 (Schneider et al., 2000).

\section{Resultados e Discussāo}

\section{Frequências alélicas}

Os valores das frequências alélicas para os três polimorfismos, nas populações da região Centro de Portugal e dos Açores são apresentados na tabela 1. Os valores observados em todos os marcadores estão de acordo com o formalismo de Hardy-Weinberg $(P>0,05)$.

Tabela 1. Frequências alélicas e outros parâmetros estatísticos dos três polimorfismos intragénicos do gene MJD1 estudados em amostras aleatórias de individuos saudáveis, não aparentados e nāo pertencentes a famílias MJD, da região Centro de Portugal e dos Açores.

\begin{tabular}{lccc}
\hline Polimorfismos & \multirow{2}{*}{ Alelos } & \multicolumn{2}{c}{ Frequências alélicas } \\
\cline { 3 - 4 } & & Centro de Portugal & Açores \\
\hline $669 A / G$ & $669 A$ & 0,201 & $\mathrm{~N}=45$ \\
& $669 G$ & 0,799 & 0,178 \\
& & $P=1,000$ & 0,822 \\
Heterozigotia & & $0,3237 \pm 0,0387$ & $P=0,3165(\mathrm{dp}=0,001)$ \\
\hline $987 C / G$ & & $\mathrm{~N}=85$ & $0,2956 \pm 0,0521$ \\
& $987 C$ & 0,159 & $\mathrm{~N}=45$ \\
& $987 G$ & 0,842 & 0,189 \\
Heterozigotia & & $P=0,2085(\mathrm{dp}=0,001)$ & 0,811 \\
\hline $1118 \mathrm{~A} / \mathrm{C}$ & & $0,2688 \pm 0,0383$ & $P=1,000$ \\
& & $\mathrm{~N}=85$ & $0,3099 \pm 0,0516$ \\
& $1118 \mathrm{~A}$ & 0,181 & $\mathrm{~N}=45$ \\
& $1118 \mathrm{C}$ & 0,819 & 0,200 \\
Heterozigotia & & $P=0,2723(\mathrm{dp}=0,001)$ & $P=0,6645(\mathrm{dp}=0,001)$ \\
& & $0,2987 \pm 0,0389$ & $0,3236 \pm 0,0508$ \\
\hline
\end{tabular}


Na população da regiāo Centro de Portugal os marcadores polimórficos apresentam frequências de $80 \%, 85 \%$ e $82 \%$ para os alelos mais comuns $669 \mathrm{G}, 987 \mathrm{G}$ e $1118 \mathrm{C}$, respectivamente. Nos Açores, a frequência obtida para os alelos mais comuns $669 \mathrm{G}, 987 \mathrm{G}$ e $1118 \mathrm{C}$, foi de $82 \%, 81 \%$ e $80 \%$, respectivamente.

O teste exacto baseado nas frequências alélicas, não mostrou diferenças significativas entre os dois grupos populacionais para nenhum dos marcadores estudados, pelo que podemos considerar ambas as populações como semelhantes em termos de distribuição alélica dos polimorfismos do gene $M . D I$ l $(P=0,58 \pm 0,01$ para o polimorfismo $669 \mathrm{~A} / \mathrm{G} ; P=0,38 \pm$ 0,02 para o polimorfismo $987 \mathrm{C} / \mathrm{G} ; P=0,56 \pm 0,01$ para o polimorfismo $1118 \mathrm{~A} / \mathrm{C})$.

Os valores de frequências alélicas obtidos são semelhantes às frequências descritas por Maciel et al. (1999) para os polimorfismos 987C/G e $1118 \mathrm{~A} / \mathrm{C}$ numa população controlo Açoriana, mas significativamente diferentes $(P=0,047)$ dos valores obtidos para o polimorfismo $669 \mathrm{~A} / \mathrm{G}$, no qual o alelo $\mathrm{G}$ registou uma frequência de 92\% (Maciel et al., 1999). Os valores obtidos para os polimorfismos $987 \mathrm{C} / \mathrm{G}$ e $1118 \mathrm{~A} / \mathrm{C}$ são também da mesma ordem de grandeza dos valores obtidos por diversos autores noutras populações Europeias (Igarashi et al., 1996; Stevanin et al., 1997).

\section{Análise de Haplótipos}

As duas amostras populacionais foram testadas em conjunto para a existência de desequilíbrio gamético entre polimorfismos. Para todos os pares de marcadores foram registados valores de $P$ abaixo do nivel de significância $(P<0,05)$ o que traduz a presença de desequilíbrio gamético entre alelos. Para o par de polimorfismos $669 \mathrm{~A} / \mathrm{G}$ e $987 \mathrm{C} / \mathrm{G}$, foram observados 3 haplótipos: o haplótipo mais comum 669G-987G com uma frequência de $95,1 \%$, seguindo-se o haplótipo complementar $669 \mathrm{~A}-987 \mathrm{C}$ $(3,7 \%)$ e o haplótipo 669A-987G $(1,2 \%)\left(\chi^{2}=42,48 ; P=0,000 ; 1\right.$ g.l. $)$. No par polimórfico 669A/G e $1118 \mathrm{~A} / \mathrm{C}$ foram observados os 4 haplótipos possíveis: o haplótipo mais comum $669 \mathrm{G}-1118 \mathrm{C}(92,1 \%)$, o seu complementar 669A-1118A $(4,9 \%)$ e dois haplótipos novos 669G-1118A $(0,6 \%)$ e 669A-1118C $(2,4 \%)\left(\chi^{2}=42,43 ; P=0,000 ; 1\right.$ g.l.). A análise do par polimórfico $987 \mathrm{C} / \mathrm{G}$ e $1118 \mathrm{~A} / \mathrm{C}$, registou o haplótipo comum $987 \mathrm{G}$ - 
$1118 \mathrm{C}(93,7 \%)$, o seu complementar 987C-1118A (5,7\%) e o haplótipo novo 987G-1118A $(0,6 \%)\left(\chi^{2}=70,08 ; P=0,000 ; 1\right.$ g.l. $)$.

Considerando os três polimorfismos em conjunto $(669 \mathrm{~A} / \mathrm{G}-987 \mathrm{C} / \mathrm{G}$ - $1118 \mathrm{~A} / \mathrm{C}$ ), foram encontrados 4 haplótipos diferentes na região Centro de Portugal e 3 nos Açores. O haplótipo mais comum 669G-987G-1118C (G-G-C) apresenta frequências de $82 \%$ e $80 \%$ na Região Centro e nos Açores, respectivamente. Segue-se o seu haplótipo complementar 669A$987 \mathrm{C}-1118 \mathrm{~A}$ (A-C-A), com frequências de $15,6 \%$ e $18,9 \%$ na região Centro e nos Açores, respectivamente. Na região Centro, foram ainda encontrados os haplótipos 669A-987G-1118C (A-G-C) e 669G-987C$1118 \mathrm{~A}$ (G-C-A) com frequências de $1,6 \%$ e $0,8 \%$, respectivamente. Nos Açores foi também encontrado o haplótipo 669G-987G-1118A (G-G-A), com uma frequência de $1,1 \%$.

Estes dados diferem de algum modo dos resultados obtidos por Gaspar et al. (2001) que encontrou numa população controlo de origem étnica diversa, os 8 haplótipos possíveis para os três locais polimórficos. Destes, o haplótipo G-G-C registou a maior frequência ( $38 \%$ ), mas o seu haplótipo complementar A-C-A registou apenas uma frequência de $2 \%$, inferior à frequência obtida para todos os restantes haplótipos raros (Gaspar et al., 2001). Os nossos resultados apontam como haplótipos originais, os haplótipos comuns complementares G-G-C e A-C-A, a partir dos quais todos os outros haplótipos raros se deverão ter originado por recombinação.

Nas famílias com MJD distribuídas pelo mundo, de origem não Portuguesa ou naturais de países não ligados a Portugal, a mutação causadora da doença foi encontrada associada ao haplótipo A-C-A em 87,30\% dos genes expandidos (Gaspar et al., 2001). As excepções, mostraram ligações ao haplótipo G-G-C em $6,35 \%$ dos genes mutados no Japão e nos Estados Unidos, ao haplótipo A-G-A em 4,76\% dos genes mutados nos Estados Unidos e Marrocos e ao haplótipo G-G-A em 1,59\% dos genes mutados na Guiana Francesa (Gaspar et al., 2001). Nas famílias com MJD de Portugal continental, os haplótipos A-C-A e G-G-C associados a genes mutados registam frequências de cerca de 50\% cada (Gaspar et al., 2001). Por outro lado, na populaçāo Açoriana com MJD foram encontrados os haplótipos A-C-A, exclusivo na ilha das Flores, e o haplótipo G-G-C, predominante em S. Miguel, o que sugere duas introduções da mutação no arquipélago, distribuindo-se os dois haplótipos por duas 
regiões geograficamente distintas por acção de um efeito fundador (Gaspar et al., 2001).

Esta associação da mutação MJD ao haplótipo original menos comum A-C-A em populações não Portuguesas espalhadas por diversos países da Europa, Ásia e América (Gaspar et al., 2001), aponta para uma origem antiga e única da mutação neste haplótipo, provavelmente numa época anterior à separação dos grupos étnicos asiático e europeu. A associação do haplótipo G-G-C à mutação MJD, característica das famílias Portuguesas, terá uma origem bem mais recente, possivelmente por um mecanismo de recombinação ou conversāo génica entre genes homólogos (Richard e Pâques, 2000), envolvendo um gene mutado A-C-A e um gene normal comum G-G-C. Os dois haplótipos associados à mutação terão sido introduzidos no arquipélago dos Açores e, por acção de um efeito fundador em ilhas diferentes, originaram a distribuição dos haplótipos associados à MJD que se verifica actualmente.

\section{Agradecimentos}

Este trabalho foi em parte subsidiado pelo Ministério da Ciência e Tecnologia, através do projecto PRAXIS/PSAU/C/SAU/25/96.

\section{Bibliografia}

Bloom, H.; Beier, H.; Gross, H. S. 1987. Improved silver-staining of plant proteins, RNA and DNA in polyacrylamide gels. Electrophoresis, 8:9399.

Budowle, B.; Chakraborty, R.; Giusti, A. M.; Eisenberg, A. J.; Allen, R. C. 1991. Analysis of the VNTR locus D1S80 by the PCR followed by high resolution PAGE. American Joumal of Human Genetics, 48:137-144.

Coutinho, P.; Andrade, C. 1978. Autosomal dominant system degeneration in Portuguese families of the Azores Islands. A new genetic disorder involving cerebellar, pyramidal, extrapyramidal and spinal cord motor functions. Neurology 28:703-709.

Gaspar, C.; Lopes-Cendes, I.; Hayes, S.; Goto, J.; Arvidsson, K.; Dias, A.; Silveira, I.; Maciel, P.; Coutinho, P.; Lima, M. et al. 2001. Ancestral origins 
of the Machado-Joseph disease mutation: a worldwide haplotype study. American Journal of Human Genetics, 68:523-528.

Goto, J.; Watanabe, M.; Ichikawa, Y.; Yee, S. B.; Ihara, N.; Endo, K.; Igarashi, S.; Takiyama, Y.; Gaspar, C.; Maciel, P.; Tsuji, S.; Rouleau, G. A.; Kanazawa, I. 1997. Machado-Joseph disease gene products carrying different carboxyl termini. Neuroscience Research, 28:373-377.

Healton, E. B.; Brust, J. C. M.; Kerr, D. L.; Resor, S.; Penn, A. 1979. Familiar cerebellar ataxia, dystonia and abnormal eye movements in a non-Portuguese family. Neurology, 29:559-560.

Igarashi, S.; Takiyama, Y.; Cancel, G.; Rogaeva, E. A.; Sasaki, H.; Wakisaka, A.; Zhou, Y.X.; Takano, H.; Endo, K.; Sanpei, K. et al. 1996. Intergenerational instability of the CAG repeat of the gene for Machado-Joseph disease (MJDI) is affected by the genotype of the normal chromosome: implications for the molecular mechanisms of the instability of the CAG repeat. Human Molecular Genetics, 5:923-932.

Kawaguchi, Y.; Okamoto, T.; Taniwaki, M.; Aizawa, M.; Inoue, M.; Katayama, S.; Kawakami, H.; Nakamura, S.; Nishimura, M.; Akiguchi, I. et al. 1994. CAG expansions in a novel gene for Machado-Joseph disease at chromosome 14q32.1. Nature Genetics, 8:221-228.

Lima, L.; Coutinho, P. 1980. Clinical criteria for diagnosis of Machado-Joseph disease: report of a non-Azorean Portuguese family. Neurology, 30:319-322.

Lima, M.; Mayer, F.; Coutinho, P.; Abade, A.1998. Origins of a mutation: Population genetics of Machado-Joseph Disease in the Azores (Portugal). Human Biology, 6:1011-1023.

Luís, J.R.; Caeiro, B. 1995. Application of two STRs (VWA and TPO) to Human Population Profiling: Survey in Galicia. Human Biology, 67:789-795.

Maciel, P.; Gaspar, C.; DeStefano, A. L.; Silveira, I.; Coutinho, P.; Radvany, J.; Dawson, D. M.; Sudarsky, L.; Guimarães, J.; Loureiro, J. E. et al. 1995. Correlation between CAG repeat length and clinical features in MachadoJoseph disease. American Joumal of Human Genetics, 57:54-61.

Maciel, P.; Gaspar, C.; Guimarães, L.; Goto, J.; Lopes-Cendes, I.; Hayes, S.; Arvidsson, K.; Dias, A.; Sequeiros, J.; Sousa, A.; Rouleau, G.A. 1999. Study of three intragenic polymorphisms in the Machado-Joseph disease gene (MJD1) in relation to genetic instability of the (CAG)n tract. European Journal of Human Genetics, 7:147-156.

Maruyama, H.; Nakamura, S.; Matsuyama, Z.; Sakai, T.; Doyu, M.; Sobue, G.; Seto, M.; Tsujihata, M.; Oh-i, T.; Nishio, T. et al. 1995. Molecular features 
of the CAG repeats and clinical manifestation of Machado-Joseph disease. Human Molecular Genetics, 4:807-812.

Miller, S. A.; Dykes, D. D.; Polesky, H. F. 1988. A simple salting out procedure for extracting DNA from human nucleated cells. Nucleic Acids Research, 16:1215.

Nakano, K. K.; Dawson, D. M.; Spence, A. 1972. Machado disease. A hereditary ataxia in Portuguese emigrants to Massachusetts. Netrology, 22:49-55.

Richard, G-F.; Pâques, F. 2000. Mini- and microsatellite expansions: the recombination connection. EMBO Reports, 1:122-126.

Rosenberg, R. N.; Nyhan, W. L.; Bay, C.; Shore, P. 1976. Autosomal dominant striatonigral degeneration. A clinical, pathologic, and biochemical study of a new genetic disorder. Neurology, 26:703-714.

Schneider, S.; Roessli, D.; Excoffier, L. 2000. Arleguin: A software for population genetics data analysis. Ver 2.000. Genetics and Biometry Laboratory. Dept. of Anthropology, University of Geneva.

Sequeiros, J.; Coutinho, P. 1993. Epidemiology and clinical aspects of MachadoJoseph disease. Advances in Neurology, 61:139-153.

Silveira, I.; Lopes-Cendes, I.; Kish, S.; Maciel, P.; Gaspar, C.; Coutinho, P.; Botez M. I.; Teive, H.; Arruda, W.; Steiner, C. E. et al. 1996. Frequency of spinocerebellar ataxia type 1, dentatorubropallidoluysian atrophy, and Machado-Joseph disease mutations in a large group of spinocerebellar ataxia patients. Neurology, 46:214-218.

Sykes, B. C. 1983. DNA in heritable disease. The Lancet, 2:787-788.

Stevanin, G.; Cancel, G.; Didierjean, O.; Durr, A.; Abbas, N.; Cassa, E.; Feingold, J.; Agid, Y.; Brice, A. 1995. Linkage disequilibrium at the Machado-Joseph disease/spinal cerebellar ataxia 3 locus: evidence for a common founder effect in French and Portuguese-Brazilian families as well as a second ancestral Portuguese-Azorean mutation. American Joumal of Human Genetics, 57:1247-1250.

Stevanin, G.; Lebre, A. S.; Mathieux, C.; Cancel, G.; Abbas, N.; Didierjean, O.; Durr, A.; Trottier, Y.; Agid, Y.; Brice, A. 1997. Linkage disequilibrium between the spinocerebellar ataxia 3/Machado-Joseph disease mutation and two intragenic polymorphisms, one of which, X359Y, affects the stop codon. American Journal of Human Genetics, 60:1548-1552.

Takiyama, Y.; Nishizawa, M.; Tanaka, H.; Kawashima, S.; Sakamoto, H.; Karube, Y.; Shimazaki, H.; Soutome, M.; Endo, K.; Ohta, S. et al. 1993. The gene for Machado-Joseph disease maps to human chromosome 14q. Nature Genetics, 4:300-304. 
Woods, B. T.; Schaumburg, H. H. 1972. Nigro-spino-dentatal degeneration with nuclear ophthalmoplegia: aunique and partially treatable clinico-pathological entity. Jounal of the Neurological Sciences, 17:149-166. 